九州大学学術情報リポジトリ

Kyushu University Institutional Repository

\title{
Effects of Recycled Fiber on Paper Permanence
}

Wu, Zonghua

Institute of Polymer Science, Fujian Normal University

Chen, Shaoping

Institute of Polymer Science, Fujian Normal University

Tanaka, Hiroo

Laboratory of Industrial Chemistry of Wood, Faculty of Agriculture, Kyushu University

https://doi.org/10.5109/24313

出版情報 : 九州大学大学院農学研究院紀要. 44 (1/2)，pp.111-117，1999-11. Kyushu University バージョン：

権利関係 : 
J. Fac. Agr., Kyushu Univ., 44 (1-2), 111-117 (1999)

\title{
Effects of Recycled Fiber on Paper Permanence
}

\section{Zonghua Wu and Shaoping Chen}

\author{
Institute of Polymer Science, Fujian Normal University, Fuzhou, Fujian 350007, P. R. China
}

\author{
Hiroo Tanaka \\ Laboratory of Industrial Chemistry of Wood, Faculty of Agriculture, \\ Kyushu University, Fukuoka 812-8581 \\ (Received June 15, 1999 and accepted August 24, 1999)
}

\begin{abstract}
The accelerated aging of the papers prepared from the virgin fiber and the recycled fiber in different weight ratios was investigated in terms of brightness and MIT folding endurance. The results show that the recycled fiber did not cause sigrificant losses in paper brightness, but resulted in great decreases in MIT folding endurance of the papers. The Raman spectra of the two fibers indicate that there were not large changes in the formation of the chromophores responsible for color of the papers and the degradation of cellulose and hemicellulose in the fiber during the cycling. The Py-GC analyses of the fibers illustrate that a large amount of rosin sizes and/or polyacrylamides remained in the recycled fiber, which interfered the formation of hydrogen bonds among the fibers so that the folding endurance of the formed papers were small. The crystallinity of the recycled fiber was larger than that of the virgin fiber, and did not reharge very much during the arcelerated aging. This may be another explatation for the small folding endurance of the papers containing the recycled fiber.
\end{abstract}

\section{INTRODUCTION}

Recently recycled fiber has become an important source in pulp and paper industry. Besides being a low cost source of fiber for paper and board manufacture, the recycled fiber serves to preserve forest resources, minimize environmental pollution and contribute to water and energy conservation. More than one third of the paper in the world is made from recycled fibers (Bhardwal et al., 1995). For these reasons, many works have been made on the effects of recycled fibers on the properties of the papers (Eillis and Sedlachek, 1993; Spangenberg, 1993; Gurnagul, 1995; and Sipilainebmalm et al., 1997).

In the previous papers (McComb and Williams, 1981; Wu and Tanaka, 1998a; Wu et al., 1997), we reported that the permanence of wood-free papers was related deeply to fiber quality and papermaking additives. The neutral PPC (plain paper copier) containing $70 \%$ of recycled fiber lost much more its brightness and MIT folding endurance than the neutral PPC containing no recycled fiber during accelerated aging. To get better understanding of the effects of recycled fibers on paper permanence, the sheets were prepared from the virgin fiber and the recycled fiber in different weight ratios. The accelerated aging of the sheets was investigated in terms of brightness, MIT folding endurance and crystallinity. The changes in chemical components of the sheets during recycling and aging were measured by means of Raman spectroscopy and pyrolysis gas chromatography (Py-GC). 


\section{MATERIALS AND METHODS}

\section{Materials}

A commercial bleached hardwood kraft pulp was used as the virgin fiber. The pulp was beaten to a Canadian Standard Freeness (CSF) of $410 \mathrm{ml}$ in a TAPPI (Technical Association of the Pulp and Paper Industry) standard beater. The recycled fiber was prepared from waste papers which were made from the virgin pulp and contained rosin sizes or polyacrylamides. The waste papers were digested with $\mathrm{NaOH}(5 \%$ on paper) at $80^{\circ} \mathrm{C}$ for $1 \mathrm{~h}$, and then bleached to yield the recycled fiber under following conditions: $\mathrm{H}_{2} \mathrm{O}_{2}, 1.5 \% ; \mathrm{NaOH}, 2 \% ; \mathrm{NaSiO}_{3}, 5 \% ; \mathrm{MgSO}_{4}, 0.05 \% ; 60^{\circ} \mathrm{C} ; 2 \mathrm{~h}$.

The handsheets with the basis weight of $60 \mathrm{~g} / \mathrm{m}^{2}$ were made from the virgin pulp and the recycled fiber at different weight ratios according to TAPPI Test Method T205 om-88.

\section{Procedure for accelerated aging of the papers}

Accelerated aging of the papers was carried out according to TAPPI Test Method $\mathrm{T} 453 \mathrm{om}-89$. The papers were heated in an oven with a fan at $105^{\circ} \mathrm{C}$. The samples were taken out at desired times, and conditioned at $20^{\circ} \mathrm{C}, 65 \mathrm{RH} \%$.

The MIT folding endurance of the samples was measured according to JIS P 8115. The brightness of the samples was measured with a MINOLTA CR-200 photoelectric reflectance photometer.

\section{Raman analyses}

The Raman measurements of the papers were carried out using a Perkin-Elmer System 2000 Fourier-transform spectrometer fitted with a standard Perkin-Elmer Raman attachment and a Nd: YAG laser $(\lambda=1064 \mathrm{~nm})$. A standard $180^{\circ}$ backscatter sampling geometry was used for all the measurements. The spectra were obtained at a resolution of $4 \mathrm{~cm}^{-1}$, using an accumulation of 50 scans, over the wavenumber range from 3600 to $400 \mathrm{~cm}^{-1}$, and laser power of $600 \mathrm{~mW}$.

\section{Crystallinity measurement}

Crystallinity of the papers were estimated using a Shimadzu DC-10 X-ray diffractometer. Copper $K_{a}-$ radiation was generated at $30 \mathrm{kV}$ and 20 nĭA. The sariople was scanned through the $2 \theta$ (diffraction angle) from 5 to $45^{\circ}$ at the speed of $2 \%$ min.

\section{RESULTS AND DISCUSSION}

\section{Effects of the contents of the recycled fiber}

According to "Dictionary of Paper" (Michael, 1996), the permanence of paper refers to the retention of significant use properties, particularly folding endurance and color, over prolonged periods. The effects of the recycled fiber on paper permanence, therefore, were evaluated in terms of MIT folding endurance and brightness. The papers made from the virgin fiber and the recycled fiber in the different weight ratios were subjected to heating at $105^{\circ} \mathrm{C}$. The changes of the papers in brightness and MIT folding endurance are shown in Figs. 1 and 2 respectively.

A brightness is a relative value of a white measurement of the papers to that of a 
standard of a white plate. It can be seen from Fig. 1 that the effect of the contents of the recycled fiber in the papers on the brightness was small. The recycled fiber had the same brightness as the virgin fiber did. After being heated for 28 days, the brightness of the papers decreased from $88 \%$ to $85 \%$ as the contents of the recycled fiber in the papers increased from $0 \%$ to $100 \%$.

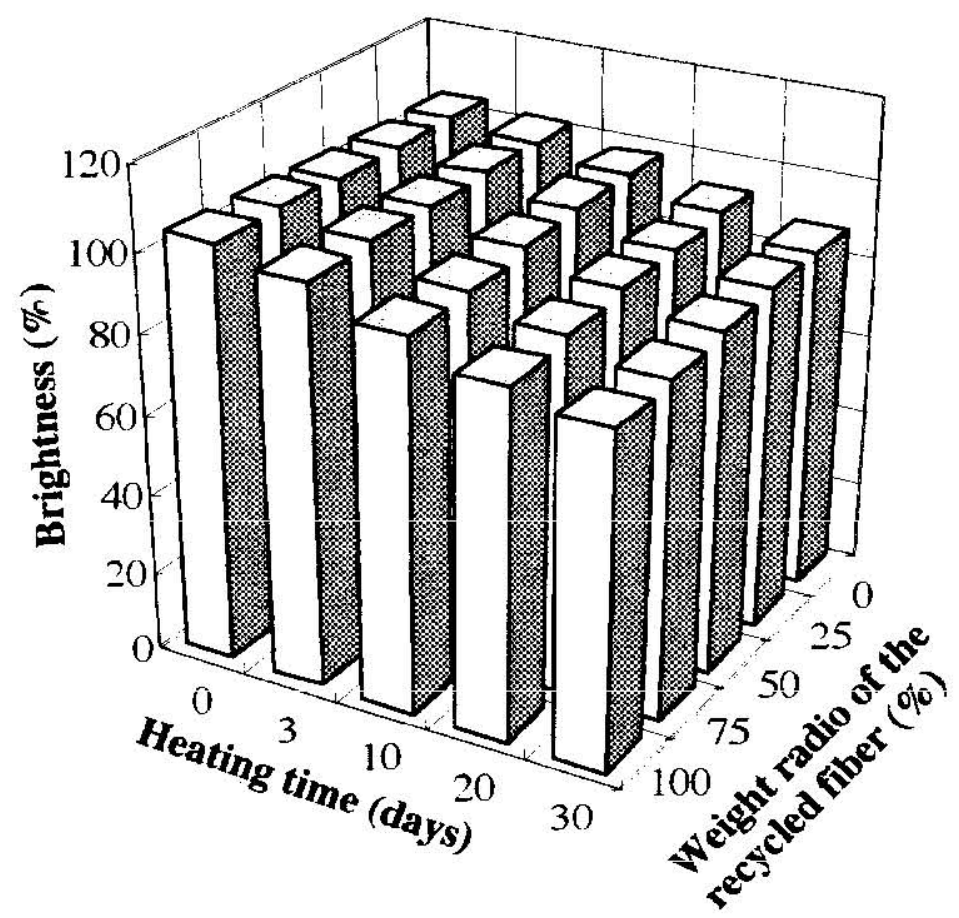

Fig. 1. Effects of the contents of the recycled pulp on brightresses of the papers.

As shown in Fig. 2, the contents of the recycled fiber significantly influenced the paper permanence. The folding cndurance of the sheet containing $25 \%$ of the recycled fiber was only half of the paper made from the virgin fiber. The increase in the contents of the recycled fiber in the paper resulted in a great decrease in the mechanical property. The folding endurance of the paper made from all of the recycled fiber fell to one fourth.

Upon heating, the papers suffered from folding endurance losses to different extents. The mechanical property of the sheet made from the virgin fiber reduced from 42 folds ( 0 days) to 29 folds ( 28 days), while those of the sheets prepared from the recycled fiber decreased from 12 folds to 8 folds. The results illustrate that the folding endurance of the recycled fiber was much smaller than that of the virgin fiber, but the percentages of its loss during the accelerated aging were similar to that of the virgin fiber. 


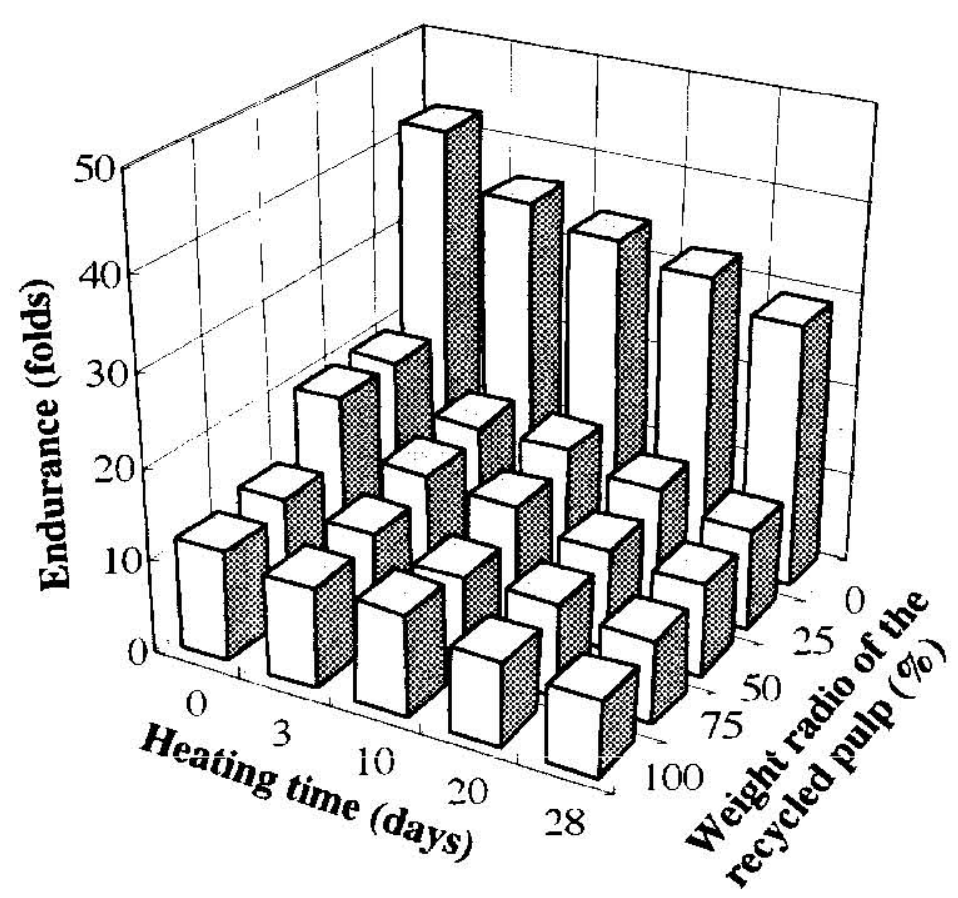

Fig. 2. Effects of the contents of the recycled pulp on MIT folding endurances of the papers.

\section{Raman spectra of the papers}

To clarify mechanisms for the effects of the recycled fiber on paper permanence, FT-Raman spectroscopy was used to analyze the chemical components in the recycled fiber. Figure 3 shows the Raman spectra of the virgin and recycled fibers. The two spectra are analogous to each other. It is generally accepted (Wu et al., 1994) that the chromophores formed in region from $1750 \mathrm{~cm}^{-1}$ to $1550 \mathrm{~cm}^{-1}$ are responsible color of the papers. There is no significant difference in the region of the two spectra, indicating that the recycling did not result in the formation of the chromophores in the fiber. This may explain that the recycled fiber had the same brightness as the virgin fiber did.

The peaks at $1126 \mathrm{~cm}^{-1}$ and $1097 \mathrm{~cm}^{-1}$ are assigned to $\alpha$ - and $\beta$-glucosidic bonds, respectively. The intensities of the peaks are related to the polymerization degrees of cellulose and hemicellulose in the fibers (Wu et al., 1997). The signal at $2900 \mathrm{~cm}^{-1}$ is arisen by $\mathrm{CH}_{2}$ which is stable against heat and light, so the band is used as inner standard to compare the intensities at $1126 \mathrm{~cm}^{-1}$ and $1097 \mathrm{~cm}^{\prime}$ of the two spectra. The intensity ratios of $I_{1226} / I_{2900}$ and $I_{1097} / I_{2990}$ in the Raman spectrum of the virgin fiber are 0.540 and 0.605 , and these in the recycled fiber are 0.538 and 0.602 , respectively. No significant 


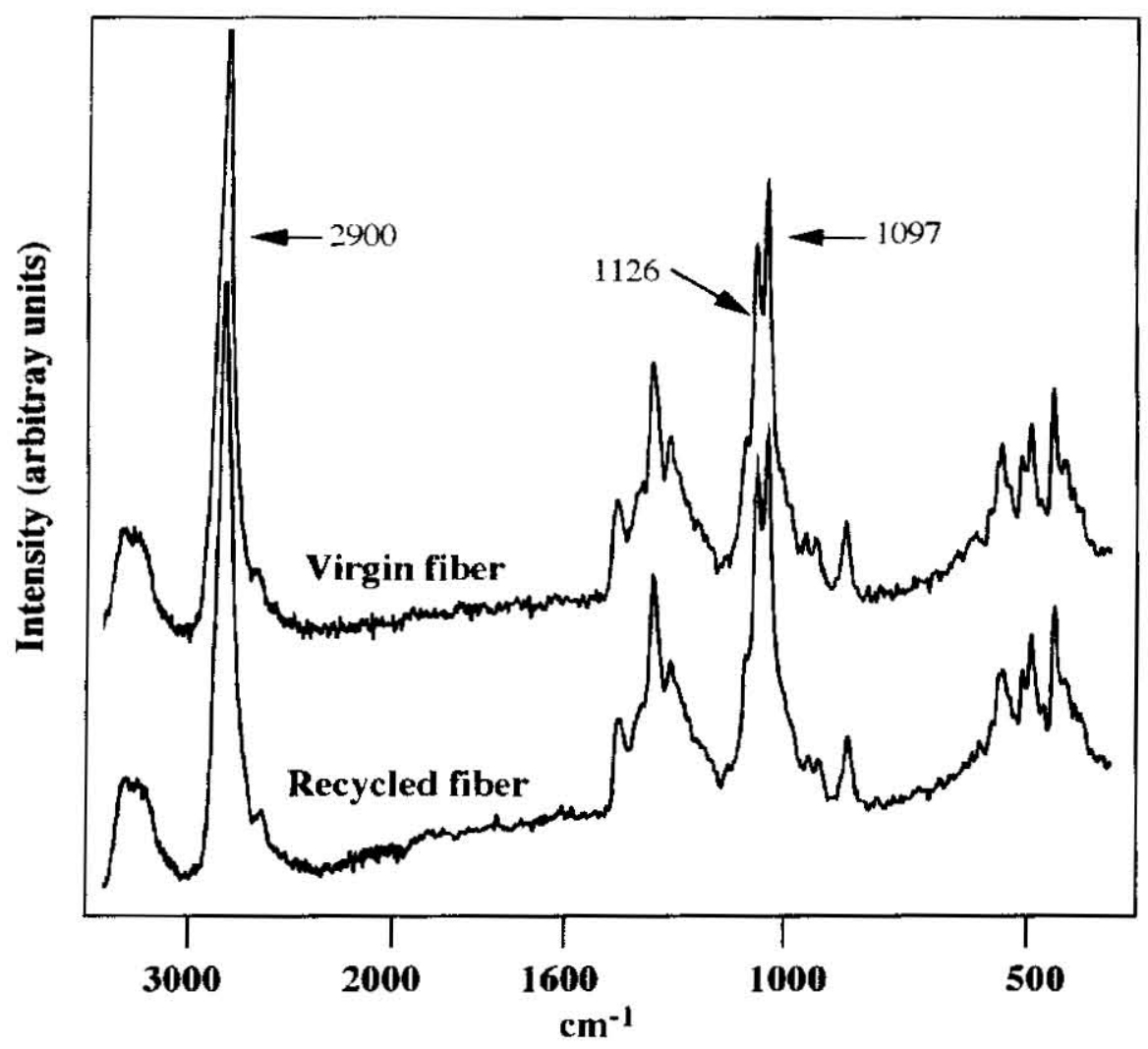

Fig. 3. Raman spectra of the virgin fiber and recycled fiber.

difference in the intensities can be seen for the two spectra, illustrating the recycling did not cause heavy degradation of cellulose and hemicellulose in the fibers.

\section{Effect of chemicals remained in the recycled fiber}

Figure 4 shows the pyrogram of the recycled fiber. Based on the previous papers (Wu and Tanaka, 1998b; Wu et al., 1997), the peaks in the region A from $36 \mathrm{~min}$ to $38 \mathrm{~min}$ were assigned to rosin sizes and polyacrylamides. The strong signals in the region indicate that a large amount of rosin sizes or polyacrylamides remained in the recycled fibers. Thus the finding gives an explanation for the small folding endurance of the papers containing the recycled fiber. The rosin sizes remained in the recycled fiber might cover on the surfaces of fibers to inhibit the hydrogen bonding between fibers. The polyacrylamides on the surfaces of the recycled fiber seemed to be those with small molecular weight due to cleavage of the main chains during the recycling, and also their functional groups might already combine with hydroxyl groups of the fiber to result in the 


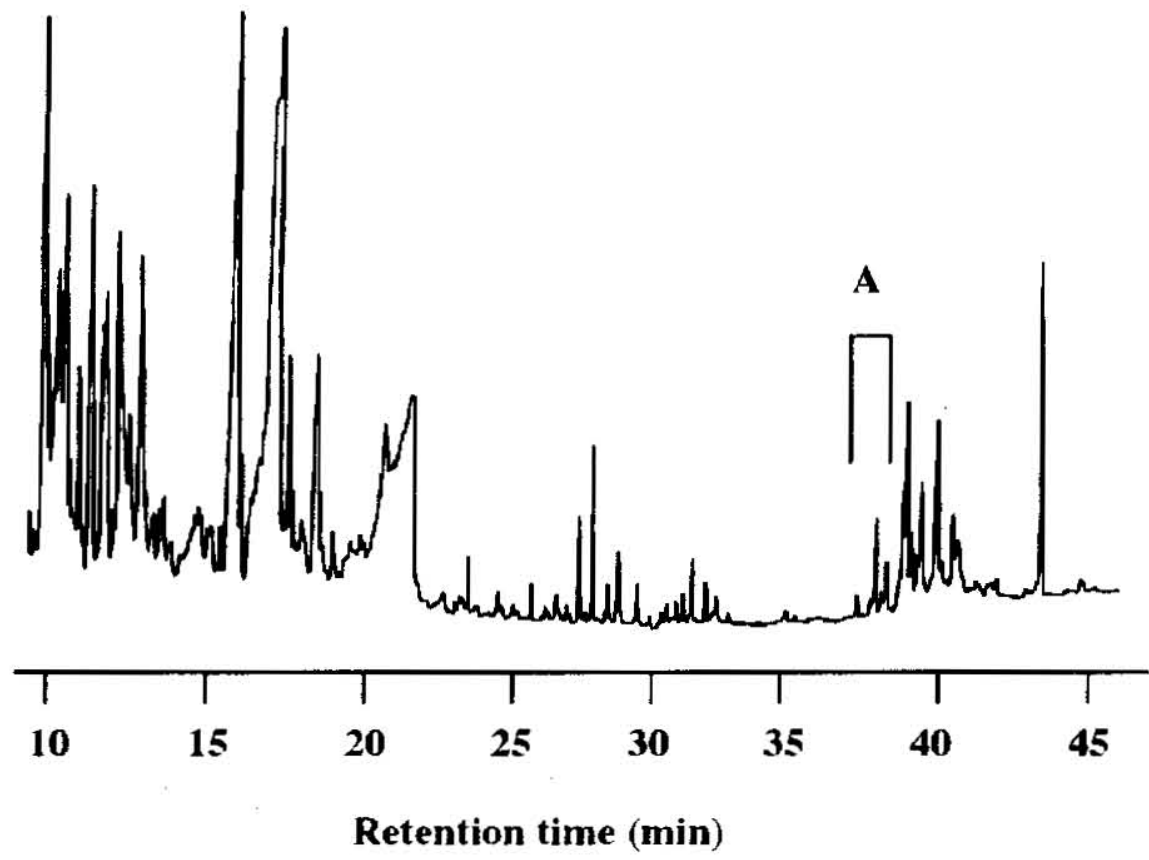

Fig. 4. The pyrogram of the recycled fiber.

outside orientation of hydrophobic parts of the polymers. Thus the papermaking additives on the surfaces of the recycled fiber interfered the formation of hydrogen bonds among the fibers so that the folding endurance of the formed papers became weak.

\section{Effect of crystallinity of the recycled fiber}

Figure 5 shows the changes in crystallinities of the papers before and after the accelerated aging. The crystallinity of the recycled fiber was $63.9 \%$, larger than $62.1 \%$ of the virgin fiber. The crystallinities of the papers increased with increasing weight radios of the recycled fiber. Since a larger crystallinity is related to a smaller folding endurance (Luner, 1969), the results may be another explanation for the decreases in the folding endurance of the papers contained the increasing amounts of the recycled fiber.

After being heated for 28 days, the crystallinities of the papers contained the recycled fiber from $0 \%$ to $100 \%$ became almost same, while the crystallinity of the virgin fiber increased from $62.1 \%$ to $63.5 \%$. This may explain that the folding endurance of the papers in larger weight ratios of the virgin fiber reduced faster during the accelerated aging. 


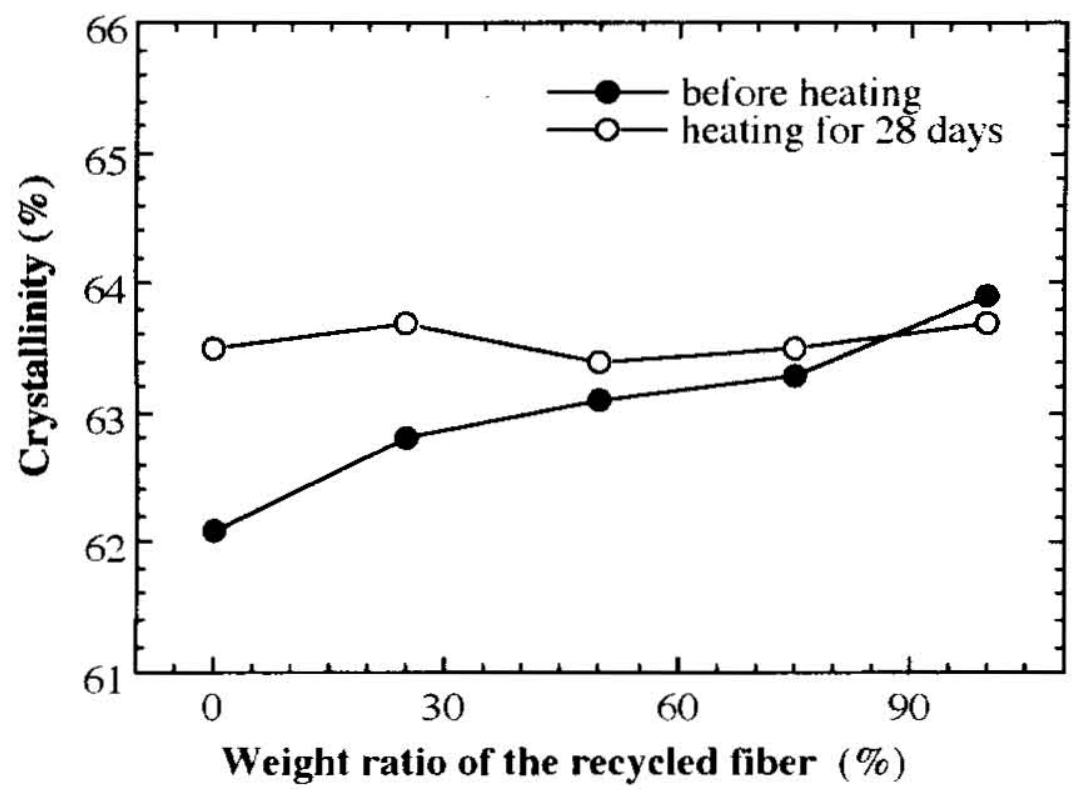

Fig. 5. Changes in crystallinity of the papers made from the virgin fiber and the recycled fiber.

\section{REFERENCES}

Bhardwal, N. K., P. Bajai and P. K. Bajai 1995 Use of enzymes to improve drainability of secondary fibers. Appita, 48: 378-380

Ellis, R. L. and K. Sedlachek 1993 Recycled vs virgin fiber characteristics: a comparison. Tappi J., 76: 143-146

Gurnagul, N. 1995 Sodium hydroxide addition during recycling: effects on fiber swelling and sheet strength. Tappi J., 78: 119-123

Luner, P. 1969 Paper Permanence. Tappi J., 52: 89-98

McComb, R. E. and J. C. Williams 1981 The value of alkaline paper for recycling. Tappi J., 64: 93-96

Michael, K. 1996 "The dictionary of paper" Tappi Press, Atlanta

Sipilainenmalm, T. et al. 1997 Purity of recycled fiber-based materials. Food Additive Contaminants, 7: $695-703$

Spangenberg, R. J. 1993 Secondary fiber recycling. Tappi Press, Atlanta

Wu, Z., Sumimoto, M. and Tanaka, H. 1994 Mechanochemistry of lignin XVIII: A novel approach to improve brightness stability of $\mathrm{H}_{2} \mathrm{O}_{3}$-bleached high-yield pulps by addition of radical scavengers to the pulping process. Holzforschung, 48: $400-404$

Wu, Z., Kawabata, K. and Tanaka, H. 1997 Permanence of neutral wood-free paper. Sci. Bull. Agr, Kyushu Univ., 52: $43-49$

Wu, Z. and Tanaka, H. 1998a Permanence of wood-free papers: Papermaking additives in naturally degraded wood-free papers. J. Wood Sci., 44: 111-115

Wu, Z. and Tanaka, H. 1998b Properties of papers sized with rosin sizes under acidic to alkaline papermaking conditions. J. Fac. Agri. Kyushu Univ. 43: 483-490 